\title{
ARTICLE \\ Convergent neural connectivity in motor impulsivity and high-fat food binge-like eating in male Sprague-Dawley rats
}

\author{
Noelle C. Anastasio ${ }^{1}$, Sonja J. Stutz ${ }^{1}$, Amanda E. Price ${ }^{1}$, Brionna D. Davis-Reyes ${ }^{1}$, Dennis J. Sholler ${ }^{1}$, Susan M. Ferguson ${ }^{2,3}$,
} John F. Neumaier ${ }^{3}$, F. Gerard Moeller ${ }^{4}$, Jonathan D. Hommel ${ }^{1}$ and Kathryn A. Cunningham (iD)

Food intake is essential for survival, but maladaptive patterns of intake, possibly encoded by a preexisting vulnerability coupled with the influence of environmental variables, can modify the reward value of food. Impulsivity, a predisposition toward rapid unplanned reactions to stimuli, is one of the multifaceted determinants underlying the etiology of dysregulated eating and its evolving pathogenesis. The medial prefrontal cortex (mPFC) is a major neural director of reward-driven behavior and impulsivity. Compromised signaling between the mPFC and nucleus accumbens shell (NAcSh) is thought to underlie the cognitive inability to withhold prepotent responses (motor impulsivity) and binge intake of high-fat food (HFF) seen in binge eating disorder. To explore the relationship between motor impulsivity and binge-like eating in rodents, we identified high (HI) and low impulsive (LI) rats in the 1-choice serial reaction time task and employed a rat model of binge-like eating behavior. HFF binge rats consumed significantly greater calories relative to control rats maintained on continual access to standard food or HFF. HI rats repeatedly exhibited significantly higher bingeing on HFF vs. LI rats. Next, we employed dual viral vector chemogenetic technology which allows for the targeted and isolated modulation of ventral mPFC (vmPFC) neurons that project to the NAcSh. Chemogenetic activation of the vmPFC to NAcSh pathway significantly suppressed motor impulsivity and binge-like intake for high-fat food. Thus, inherent motor impulsivity and binge-like eating are linked and the vmPFC to NAcSh pathway serves as a 'brake' over both behaviors.

Neuropsychopharmacology (2019) 44:1752-1761; https://doi.org/10.1038/s41386-019-0394-8

\section{INTRODUCTION}

Eating is essential for life, but repeated consumption of inappropriately large amounts of food in a brief period (i.e., binge eating) can alter the reward value of food and food-related cues and fuel binge eating cycles. Binge eating disorder (BED) is the most prevalent eating disorder in the U.S. and is linked to severe obesity, psychological disorders (e.g., anxiety, depression), and medical morbidity [1] and was recognized as a formal eating disorder in the 5th edition of the Diagnostic and Statistical Manual of Mental Disorders (DSM-5) [2]. BED is marked by recurrent, brief (e.g., 2 hours) episodes of overeating [esp., palatable high fat/sugar foods] and accompanied by a feeling of loss of control during the binge [2]. While binge eating is seen in anorexia nervosa and bulimia nervosa, BED occurs in the absence of compensatory behaviors (e.g., vomiting, laxative use, exercise) and is associated with significant psychological morbidity [2]. The results of the population-based National Comorbidity Survey Replication indicate that BED is a "major public health burden" because of its relationship to severe obesity and serious medical problems; however, BED represents its own phenotypic entity among eating disorders with specific neurobiological substrates $[3,4]$.

Both impulsivity and behavioral disinhibition factor into the multifaceted determinants that underlie the etiology of BED and its progressive pathogenesis (for review ref. [4]). Impulsivity is defined clinically as a predisposition toward rapid unplanned reactions to stimuli without regard to the negative consequences [5]. Greater impulsivity in BED individuals is observed on the clinical instrument known as the Barratt Impulsiveness Scale-11 (BIS-11) [6, 7], which assesses attentional, motor, and nonplanning factors of impulsivity. Impulsivity is associated with heightened food intake in general $[8,9]$ and greater severity of bingeing [10]. Further, treatment of BED with lisdexamfetamine suppresses both binge eating and BIS-11 scores, particularly on the motor and nonplanning impulsivity subscales [11]. Preclinical studies have also established a relationship between impulsive choice (delayed reward measures) and binge-like eating behavior [12, 13], while high trait motor impulsivity (difficulty withholding a prepotent response; motor impulsivity) predicts feeding behaviors in rats [14]. Yet, our understanding of the relationship linking motor impulsivity and binge-like eating, and their shared neurobiological mechanism, is limited.

The medial PFC (mPFC) is a major neural director of impulse control and integration of internal states with environmental cues [15]. Hypoactivity within the mPFC associates with heightened impulsivity in BED individuals during a response inhibition task [16] while active transcranial direct current stimulation targeting the PFC suppresses food craving, especially for sweet foods and carbohydrates, to a greater extent than sham conditions $[17,18]$.

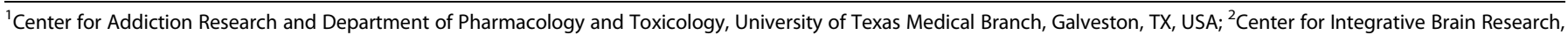

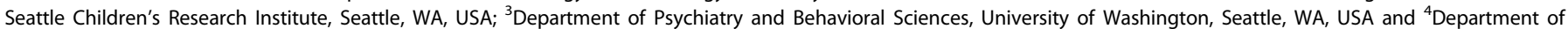
Psychiatry and Institute for Drug and Alcohol Studies, Virginia Commonwealth University, Richmond, VA, USA Correspondence: Noelle C. Anastasio (ncanasta@utmb.edu) or Kathryn A. Cunningham (kcunning@utmb.edu) 
The involvement of mPFC subcircuits in motor impulsivity is also implicated [19-21], but understudied. Chemogenetic activation of the mPFC suppresses motor impulsivity in highly impulsive mice and enhances food-seeking behaviors, but does not alter unconditioned feeding behaviors, supporting a key role for the mPFC in motor impulsivity and goal-directed behaviors [21]. A sub-region of the mPFC, the rodent ventral mPFC (vmPFC), densely innervates the NAC shell (NACSh) [22], and reduced functional activity between the vmPFC and basal ganglia [e.g., $\mathrm{NAcSh}$ ] is thought to underlie the cognitive inability to withhold motor impulsivity $[20,23]$. Taken together, we propose that the connectivity from the VmPFC to the NAcSh pathway is positioned as a putative suppression pathway such that its activation attenuates impulsivity and binge-like eating. We tested the hypotheses that inherent levels of motor impulsivity determine the magnitude of binge-like eating on high-fat food and that synthetic chemogenetic activation of the vmPFC to NAcSh monosynaptic pathway attenuates both high motor impulsivity and binge-like eating on high-fat food in rodents.

\section{MATERIALS AND METHODS}

Animals

Male, outbred Sprague-Dawley rats ( $n=145$; Envigo, Indianapolis, IN) weighing $225-275 \mathrm{~g}$ at arrival were housed two per cage (except where noted below) under a 12-h light-dark cycle (lights on between 0600 and $1800 \mathrm{~h}$ ) with controlled temperature $\left(21-23^{\circ} \mathrm{C}\right)$ and humidity $(40-50 \%)$. Animals were acclimated for 7 days to the colony room prior to the start of handling and experimental procedures. Standard food (SF) and water were available to rats ad libitum except during daily operant sessions and where noted below. Sample sizes were determined based on pilot data collected from previous cohorts and power analyses (G*Power, Germany). Group assignments were blinded to investigators who performed surgeries, ligand administration, gene manipulation, and endpoint analyses. All experiments were conducted in accordance with the NIH Guide for the Care and Use of Laboratory Animals (2011) and with the University of Texas Medical Branch Institutional Animal Care and Use Committee approval.

\section{Foods}

All food intake studies were assessed by monitoring 2-hour intake at the beginning of the dark cycle (1800-2000 h) in home cages. Standard food (SF; LM-485 Mouse/Rat Sterilizable Diet; Teklad Diets, Madison, WI) consisted of $25 \%$ protein, $58 \%$ carbohydrate, and $17 \%$ fat (by kcal). High-fat food (HFF; D12451, Research Diets, New Brunswick, NJ) contained 20\% protein, 35\% carbohydrate, and $45 \%$ fat (by kcal). Low-fat food (LFF; D12450B, Research Diets) consisted of $20 \%$ protein, $70 \%$ carbohydrate, and $10 \%$ fat (by kcal). BED is characterized by uncontrollable, recurrent episodes of excessive intake of food that is often driven by hedonic rather than homeostatic mechanisms (i.e., food intake driven by wanting and liking factors but not necessary for energy balance) [24-26]. Thus, the energy-dense high-fat (HFF; $45 \%$ fat by kcal) and highcarbohydrate (LFF; $10 \%$ fat by kcal) diets employed herein are proposed to override homeostatic feeding signals [27-32].

\section{Drugs}

Clozapine N-oxide (CNO; BML-NS105, Enzo Life Sciences, Farmingdale, NY) was dissolved in $0.9 \% \mathrm{NaCl}$ at a concentration of $2 \mathrm{mg} / \mathrm{mL}$. Clozapine (BML-D107, Enzo Life Sciences) was dissolved in $1 \%$ DMSO at a concentration of $2 \mathrm{mg} / \mathrm{mL}$.

\section{Viral vectors}

Cre-dependent viral vectors were packaged into adeno-associated (AAV) serotype 2 [hSyn-DIO-mCherry AAV or hSyn-DIO-hM3D(Gq)mCherry AAV] at the University of North Carolina Vector Core
(Chapel Hill, NC) with a titer of $3-6.1 \times 10^{12}$ viral genomes $/ \mu \mathrm{L}$. Canine adenovirus expressing Cre (CAV2-Cre) was packaged as previously described [33-35].

\section{GENERAL METHODS}

Binge-like eating paradigm

A binge-like eating model modified from the Corwin limited access palatable food protocol $[36,37]$ and validated by our groups [29-32] was employed for the current studies. Singlehoused rats $(n=131)$ received exclusive access to HFF or LFF for 1 week to reduce neophobia which was then replaced by exclusive access to SF for 1 week. At the beginning of the dark cycle $(1800 \mathrm{~h}) 1$ week after the last exposure to HFF or LFF, SF was replaced with $40 \mathrm{~g}$ of HFF or LFF. At the end of 2 hours, the HFF or LFF was removed and weighed to determine intake, and rats were given ad libitum access to SF. Non-binge SF intake was also measured in single-housed rats $(n=24)$ as previously described [29-32]. At $1800 \mathrm{~h}$, all but $40 \mathrm{~g}$ of SF was removed from the home cage. At the end of 2 hours $(2000 \mathrm{~h})$, SF was removed and weighed to determine non-binge-like intake, and rats were allowed ad libitum access to SF. Binge intake was defined as rats which consumed $\geq 5 \mathrm{~g}$ HFF in 2 hours according to previous publications [29-32].

\section{1-Choice serial reaction time (1-CSRT) task}

For motor impulsivity assessments, procedures occurred in standard five-hole nose-poke operant chambers equipped with a houselight, food tray, and an external pellet dispenser capable of delivering $45 \mathrm{mg}$ dustless precision pellets [21.3\% protein, $54.0 \%$ carbohydrate, and 3.8\% fat (by kcal); Bio-Serv, Frenchtown, NJ] housed within ventilated and sound-attenuated chambers (MedAssociates, St Albans, VT). The 1-CSRT task methodology has been described in detail previously [38-44]. Briefly, rats $(n=$ 110) were habituated to the test chamber; a nose-poke into the singly-illuminated center hole resulted in the delivery of one food pellet into the magazine on the opposite wall of the chamber and simultaneous illumination of the magazine light. The training stages were each comprised of daily sessions of 100 trials to be completed in a maximum of $30 \mathrm{~min}$; each training stage (10 total) involved incrementally lowering the stimulus duration with a 5-s limited hold and an intertrial interval (ITI) of $5 \mathrm{~s}$ (ITI5). A maximum of 100 correct responses in a session resulted in a maximum of 100 reinforcers earned; incorrect "non-target" responses, premature responses, or omissions resulted in a time-out period ( $5 \mathrm{~s}$ ) that reduced the potential number of reinforcers delivered. Advancement to the next training stage required rats to meet acquisition criteria: $\geq 50$ correct responses, $>80 \%$ accuracy [correct responses/ (correct + incorrect) $\times 100]$, and $<20 \%$ omissions (omitted responses/trials completed $\times 100$ ) [38-44].

The number of premature responses, omissions, and reinforcers earned, percent accuracy, latency to first response, and time to finish the 1-CSRT task were recorded. Premature responses, the primary output measure to assess motor impulsivity, were categorized into three types: target, non-target, and total (target + non-target). The number of reinforcers earned provides a measure of task competency and a secondary assessment of motor impulsivity, while percent accuracy was a general indication of attentional capacity. Percent omissions indicated failures of detection of the visual stimuli in the center hole as well as motivation to perform the task. Throughout the acquisition and maintenance of this task, rats were food restricted to $90 \%$ freefeeding weight.

Intracranial viral-mediated gene transfer

Rats $(n=72)$ were anesthetized intramuscularly with a cocktail containing xylazine $(8.6 \mathrm{mg} / \mathrm{kg})$, acepromazine $(1.5 \mathrm{mg} / \mathrm{kg})$, and ketamine $(43 \mathrm{mg} / \mathrm{kg})$ in bacteriostatic saline and placed in a 
stereotaxic apparatus with the upper incisor bar at $-3.8 \mathrm{~mm}$ below the interaural line. AAV-hSyn-DIO-hM3D-mCherry or AAVhSyn-DIO-mCherry was bilaterally infused into the vmPFC; [45] the coordinates targeted were $\mathrm{AP}+3.0 \mathrm{~mm}, \mathrm{ML}+1.8 \mathrm{~mm}$, and $\mathrm{DV}$ $-5.1 \mathrm{~mm}$ from skull at a $15^{\circ}$ angle. CAV2-Cre-eGFP was bilaterally infused into the NAcSh; [45] the coordinates targeted were $\mathrm{AP}+1.4 \mathrm{~mm}, \mathrm{ML}+3.0$, and $\mathrm{DV}-7.8 \mathrm{~mm}$ from skull at a $15^{\circ}$ angle. Viral vectors were infused using 28 gauge Hamilton microsyringes (Hamilton Company, Reno, NV) at $0.1 \mu \mathrm{L} / \mathrm{min}$ over $10 \mathrm{~min}$ for a total of $1 \mu \mathrm{L}$ per infusion. The microsyringes remained in place for an additional $10 \mathrm{~min}$ to allow for adequate diffusion prior to removal. Rats were allowed 3 weeks to recover and to allow for stable transgene expression prior to initiation of behavioral assays; AAV infection demonstrates stability for at least 12-18 months post-infection [46]. All rats which received intracranial viral microinfusion were assessed for viral placement confirmation via visualization of mCherry in the vmPFC using immunohistochemistry $(n=22)$ or rapid-visualization flashlight photography $(n=50)$ (see below for details). Thirty-six animals were excluded from the final data analyses due to misplacement.

\section{Immunohistochemistry}

Viral vector placement confirmation via visualization of mCherry immunohistochemistry was assessed ( $n=22$ rats) at the conclusion of behavioral experiments. Rats were anesthetized $(100 \mathrm{mg} / \mathrm{kg}$ sodium pentobarbital, i.p.) and transcardially perfused with phosphate buffered saline (PBS) followed by $3 \%$ paraformaldehyde. Brains were removed, post-fixed in $3 \%$ paraformaldehyde for $4 \mathrm{~h}$ at $4{ }^{\circ} \mathrm{C}$, cryoprotected in $30 \%$ sucrose for $72 \mathrm{~h}$ at $4{ }^{\circ} \mathrm{C}$ until brains sank, and stored at $-80^{\circ} \mathrm{C}$ until further use. Free-floating coronal sections at the level of the vmPFC $(30 \mu \mathrm{m})$ were mounted, and slides were coverslipped with Vectashield fluorescent mounting media with DAPI (Vector Laboratories, Burlingame, CA) according to previous publications [40, 41, 47, 48]. Images were acquired using a Leica DFC3000 wide field camera and Leica Application Suite (Leica Mircosystems, Wetzlar, Germany). mCherry expression throughout the vmPFC had to be detected in at least 25 cell bodies for inclusion of an animal in the analyses [34].

\section{Immunoblotting}

The ability of CNO to elicit cellular activation of the vmPFC was assessed at the conclusion of behavioral experiments. Rats ( $n=$ 50) were anesthetized ( $400 \mathrm{mg} / \mathrm{kg}$ chloral hydrate, i.p.) and decapitated within four minutes of onset of the anesthetic plane. Brains were extracted and sliced into 1-mm-thick coronal sections to determine viral vector placement via visualization of mCherry. A DFP-1 Dual Fluorescent Protein Flashlight and VG2 barrier filter glasses (Nightsea, Bedford, MA) [40,41] were used to visualize red fluorescence. Photographs were taken with a Nikon D7100 digital single lens reflex camera equipped with a macro lens and red filter. Microdissections of the vmPFC containing red fluorescence throughout (i.e., mCherry+) and NAcSh were completed over ice [45]. Tissue was flash frozen in liquid nitrogen and stored at $-80^{\circ} \mathrm{C}$ for subsequent protein extraction.

Protein from rats with accurate placement and expression $(n=$ 16) was extracted by homogenizing samples in 10 times $\mathrm{w} / \mathrm{v}$ extraction buffer (20 mM HEPES, $200 \mathrm{mM} \mathrm{NaCl}, 1 \mathrm{mM}$ EDTA, $1 \mathrm{mM}$ EGTA, and $1 \mathrm{mM}$ DTT) plus protease inhibitor cocktail and phosphatase inhibitor 2 and 3 cocktails $(10 \mu \mathrm{L} / \mathrm{mL})$. The total homogenate was centrifuged at $1000 \times g$ for $10 \mathrm{~min}$ at $4{ }^{\circ} \mathrm{C}$. The postnuclear supernatant was removed and probed for specific protein expression using the Wes ${ }^{\mathrm{TM}}$ automated western blotting system (ProteinSimple, San Jose, CA), which utilizes capillary electrophoresis-based immunodetection $[40,43,49]$. Wes ${ }^{\mathrm{TM}}$ reagents (biotinylated molecular weight marker, streptavidinHRP fluorescent standards, luminol-S, hydrogen peroxide, sample buffer, DTT, stacking matrix, separation matrix, running buffer, wash buffer, matrix removal buffer, secondary antibodies, antibody diluent, and capillaries) were obtained from the manufacturer (ProteinSimple) and used according to the manufacturer's recommendations. Equal amounts of protein $(4 \mu \mathrm{g})$ were combined with $0.1 X$ sample buffer and $5 X$ master mix (200 mM DTT, $5 X$ sample buffer, $5 X$ fluorescent standards), gently mixed, and then denatured at $90^{\circ} \mathrm{C}$ for $10 \mathrm{~min}$. Levels of cFOS were assessed using a monoclonal mouse antibody (sc-253; Santa Cruz Biotechnology, Dallas, TX) at a concentration of 1:1000. Separation electrophoresis $\left(375 \mathrm{~V}, 31 \mathrm{~min}, 25^{\circ} \mathrm{C}\right)$ and immunodetection in the capillaries were fully automated using the following settings: separation matrix load for 200-s, stacking matrix load for 20-s, sample load for 12-s, antibody diluent for $30 \mathrm{~min}$, primary antibody incubation for $60 \mathrm{~min}$, secondary antibody incubation for $30 \mathrm{~min}$, and chemiluminescent signal exposure for 30-s, 60-s, 120-s, 240-s, and 480-s. Data analyses were performed using the Compass Software (ProteinSimple). The Western blot analysis signal is defined as the area under the curve for the cFOS peak normalized to total protein per capillary and representative "virtual blot" electrophoretic images for cFOS were automatically generated by the Compass Software (ProteinSimple).

\section{RESEARCH DESIGN}

Limited access to HFF induces binge-like eating behavior

To demonstrate that limited access to HFF induces binge-like eating behavior, rats $(n=24)$ were single-housed and divided into three groups. Group 1 received exclusive continual access to SF for 14 days. Group 2 received exclusive continual access to HFF for 14 days. Group 3 received exclusive continual access to HFF for 7 days, then exclusive continual access to SF for 7 days. Immediately following the 14-day feeding regimen, 2-hour SF (Group 1) or HFF (Groups 2 and 3) intake was measured in the home cage.

Inherent impulsivity predicts HFF binge-like eating After meeting stability criteria for the final training stage in the 1CSRT task over three consecutive ITI5 sessions (with $<20 \%$ variability, approximately days 25-30), an ITI8 challenge session was conducted in which the ITI was 8-s for the session $[40,41,43,50]$. High impulsive (HI) and low impulsive (LI) rats ( $n=12$ /phenotype) were defined with a median split [51-53] of premature responses assessed on the ITI8 challenge. Upon completion of phenotyping, rats were single-housed and received unlimited access to SF for 14 days. On day 14, 2-hour SF intake was recorded. Rats were then given exclusive continual access to HFF for 7 days followed by exclusive continual access to SF for 7 days. Immediately following the 14-day feeding regimen, 2-hour HFF intake was recorded. Rats were then given exclusive continual access to LFF for 7 days followed by exclusive continual access to SF for 7 days. Immediately following the 14-day feeding regimen, 2-hour LFF intake was recorded. All intake was recorded over the first 2 hours of the dark cycle (1800-2000 h).

The vmPFC to NAcSh pathway regulates motor impulsivity and HFF binge-like eating

To study the role of vmPFC connectivity in these behaviors, we employed a dual viral vector strategy $[35,54]$ to express an excitatory hM3D DREADD (Designer Receptor Exclusively Activated by Designer Drug, "M3D") selectively in vmPFC neurons that project to the NAcSh in male rats trained to stability on the 1-CSRT task. Three weeks after surgery, rats were trained to stability on the 1-CSRT task. Upon task acquisition and maintenance, rats were tested on ITI5 sessions $20 \mathrm{~min}$ after treatment of either vehicle ( $1 \mathrm{~mL} / \mathrm{kg}$ saline, i.p.) or CNO (2 mg/kg, i.p.); all treatments were administered in a randomized, counterbalanced manner. Operant training was then terminated and rats were single-housed. Rats were given exclusive continual access to SF for 14 days followed 
by exclusive continual access to HFF for 7 days then exclusive continual access to SF for 7 days (as described above). Immediately following this feeding regimen, rats were assessed in the HFF binge-like paradigm. Rats received either vehicle ( $1 \mathrm{~mL} / \mathrm{kg}$ saline, i.p.) or CNO (2 mg/kg, i.p.) at $1740 \mathrm{~h}$ on each of 2 days spaced 7 days apart. At $1800 \mathrm{~h}$, SF was replaced with $40 \mathrm{~g}$ HFF. The remaining HFF was weighed at $2000 \mathrm{~h}$, and 2-hour HFF binge-like intake was recorded. To assess CNO specificity to the M3D system on 1-CSRT task performance and HFF binge-like intake, two separate groups of surgically naïve rats (i.e., M3D-lacking) were treated with CNO $(2 \mathrm{mg} / \mathrm{kg})$, clozapine ( $2 \mathrm{mg} / \mathrm{kg}$ ) or the appropriate vehicle $20 \mathrm{~min}$ prior to the start of an ITI5 session (for 1 -CSRT task-trained rats; $n=6$ ) or $2 \mathrm{~h}$ HFF bingelike session $(n=10-11)$. All treatments were administered in a randomized, counterbalanced within or between subject design.

\section{Statistical analyses}

Outcome measures from the 1-CSRT task and feeding studies were assessed by Student's $t$-test or analysis of variance (ANOVA) as appropriate to research design. A two-way repeated measures ANOVA was used to assess outcome measures from 1-CSRT task and feeding studies in virally transduced rats. Based upon preliminary data and published literature, a priori comparisons were specifically defined prior to the start of the experiment and were assessed with the Sidak test (for multiple pairwise comparisons of means). A Student's $t$-test was employed to compare cFOS expression $60 \mathrm{~min}$ after vehicle or CNO administration. The specificity of CNO or clozapine for the M3D system on 1-CSRT task measures and HFF binge-like intake was analyzed using a Student's $t$-test. All statistical analyses were performed in GraphPad Prism (Version 7) with an experiment-wise error rate of $a=0.05$.

\section{RESULTS}

HFF binge-like eating is observed in rats

Binge-like intake of HFF was assessed in a validated HFF intermittent access model [29-32]. A main effect of diet on binge-like intake was detected $\left(F_{2,21}=7.04 ; p<0.05\right)$; a priori comparisons demonstrated greater intake of HFF after limited access compared to continual access of HFF (Fig. 1a; $p<0.05$ ) or SF after continuous access (Fig. 1a; $p<0.05$ ). There was no difference in intake of continual access SF vs. continual access HFF (Fig. 1a; n.s.). No main effect of diet on body weight was detected (Fig. $1 \mathrm{~b}$; $F_{2,21}=1.1 ;$ n.s.). These results are in agreement with previously published studies which report rats with continual access to HFF consume $\leq 4 \mathrm{~g}$ of HFF in 2 hours whereas rats subjected to limited access to HFF consume $\geq 5 \mathrm{~g}$ of HFF in 2 hours (i.e., binge-like intake) [29-32].

High inherent motor impulsivity predicts HFF binge-like eating Rats were ranked as high (HI; $n=12$ ) or low impulsive (LI; $n=12$; median split) based upon total (target+non-target) premature responses on an ITI8 1-CSRT task challenge session; the ITI8 session augments impulsive responding and more readily allows for the identification of phenotypic differences in an outbred rat population $[40,41,43,44,55-58]$. $\mathrm{HI}$ rats made more total premature responses vs. LI rats (Fig. 2a; $p<0.05$ ) and earned fewer reinforcers (Fig. 2b; $p<0.05$ ). Further, $\mathrm{HI}$ rats demonstrated lower percent omissions (Fig. $2 c ; p<0.05$ ) vs. LI rats, suggesting that the motivation to perform the task is heightened in $\mathrm{HI}$ vs. $\mathrm{LI}$ rats. $\mathrm{HI}$ rats made more target premature responses $(p<0.05)$ and completed the ITI8 session faster $(p<0.05)$ vs. LI rats (Supplementary Table 1). Non-target premature responses (n.s.), accuracy (n.s.), and the latency to the first pellet (n.s.) on the ITI8 session were not significantly different between $\mathrm{LI}$ and $\mathrm{HI}$ rats (Supplementary Table 1), suggesting that all rats effectively detected the task stimuli and performed as trained. Together, these data support the utility of the 1-CSRT task to reliably and consistently identify inherent variance in motor impulsivity levels in an outbred rat population.

Following phenotype identification on the 1-CSRT task, $\mathrm{HI}$ and $\mathrm{LI}$ were subjected to SF continual access, HFF binge-like intake, and LFF binge-like intake feeding paradigms under freely fed conditions. SF continual access intake did not differ between $\mathrm{HI}$ and $\mathrm{LI}$ rats (Fig. $2 \mathrm{~d} ; t_{19}=0.64 ;$ n.s.). $\mathrm{HI}$ rats exhibited higher HFF intake (Fig. $2 \mathrm{e} ; t_{19}=2.12 ; p<0.05$ ), but not LFF intake (Fig. $2 \mathrm{f}$; $t_{19}=0.52 ;$ n.s.) vs. LI rats. A two-way repeated measures ANOVA revealed no main effect of phenotype $\left(F_{1,19}=0.00063\right.$; n.s.), a main effect of feeding paradigm $\left(F_{2,38}=8.98 ; p<0.05\right)$, but no phenotypexfeeding paradigm interaction $\left(F_{2,38}=0.86\right.$; n.s. $)$ on body weight (Fig. $2 \mathrm{~g}$ ). Body weights following SF continual access intake (n.s.), HFF intake (n.s.) or LFF intake (n.s.) did not differ between $\mathrm{HI}$ and $\mathrm{LI}$ rats.

Activation of the vmPFC to NAcSh pathway suppresses motor impulsivity and HFF binge-like eating

We employed a Cre-dependent viral vector based "double-floxed" inverted open reading frame (DIO) switch system to express an engineered $\mathrm{Ga}_{\mathrm{q}}$ (M3D) DREADD $[35,54]$ selectively in vmPFC neurons that project to the NAcSh (Fig. 3a). In the presence of Cre, the loxP sites are excised and the transgene is inverted into the sense direction and expressed from the $h$ Syn (synapsin, neuronal specific) promoter (Fig. 3a) $[35,54,59]$. The DIO-mCherry AAV or DIO-M3D-mCherry AAV were infused into the vmPFC site while a canine adenovirus-2 (CAV)-Cre axonal retrograde viral vector was infused into the aligned NACSh region of the same rat. Accurate localization of M3D within the VmPFC was determined via visualization of mCherry using either a DFP-1 dual fluorescent protein flashlight (Fig. 3a, inset) or fluorescent microscopy (Fig. 3b, c). Stable transgene expression of the DIO-mCherry AAV (Fig. 3b) or DIO-M3D-mCherry AAV (Fig. 3c) was restricted to vmPFC neurons that project to the NAcSh. Figure $3 d$ demonstrates bilateral mCherry expression in the vmPFC for either the DIOmCherry AAV or M3D-mCherry AAV rats and the extent of the viral spread on a rostrocaudal gradient.

We found that CNO administration to M3D-transduced rats significantly enhanced cFOS protein levels in the vmPFC and NAcSh vs. vehicle administration (Fig. 3e). A two-way ANOVA revealed no main effect of viral vector $\left(F_{1,12}=3.79\right.$; n.s.), a main effect of CNO treatment $\left(F_{1,12}=9.24 ; p<0.05\right)$, and a viral vector $\times$ CNO treatment interaction $\left(F_{1,12}=5.65 ; p<0.05\right)$ for $\mathrm{cFOS}$ levels in the vmPFC. vmPFC cFOS levels in the DIO-mCherry rats were not different between vehicle and CNO treatments (Fig. 3e; n.s.); CNO administration induced an $\sim 3$-fold increase in vmPFC cFOS levels vs. vehicle in M3D-mCherry rats (Fig. 3e; $p<0.05$ ). A two-way ANOVA revealed no main effect of viral vector $\left(F_{1,12}=\right.$ 1.88 ; n.s.), no main effect of CNO treatment $\left(F_{1,12}=3.43\right.$; n.s.), but a viral vector $\times$ CNO treatment interaction $\left(F_{1,12}=5.37 ; p<0.05\right)$ for cFOS levels in the NAcSh. NAcSh cFOS levels in the DIO-mCherry rats were not different between vehicle and $\mathrm{CNO}$ treatments (Fig. 3e; n.s.); CNO administration induced an approximate 2.5 -fold increase in NAcSh cFOS levels vs. vehicle in M3D-mCherry rats (Fig. 3e; $p<0.05$ ). Taken together, these data indicate cellular activation of the VmPFC and NAcSh following CNO administration as well as the specificity of CNO for the M3D system.

Stimulation of the vmPFC to NAcSh circuit with systemic CNO significantly reduced impulsive behavior on the 1-CSRT task (Fig. 4). No main effect of viral vector $\left(F_{1,28}=0.017\right.$; n.s.) or CNO treatment $\left(F_{1,28}=2.08 ;\right.$ n.s. $)$, but a viral vectorxtreatment interaction $\left(F_{1,28}=4.52 ; p<0.05\right)$ for total premature responses was detected (Fig. 4a). A priori comparisons demonstrated no difference between CNO and vehicle on total premature responses in the DIO-mCherry rats (Fig. 4a; n.s.); CNO administration attenuated total premature responses vs. vehicle in the M3Dtransduced rats (Fig. 4a; $p<0.05$ ). No main effect of viral vector 

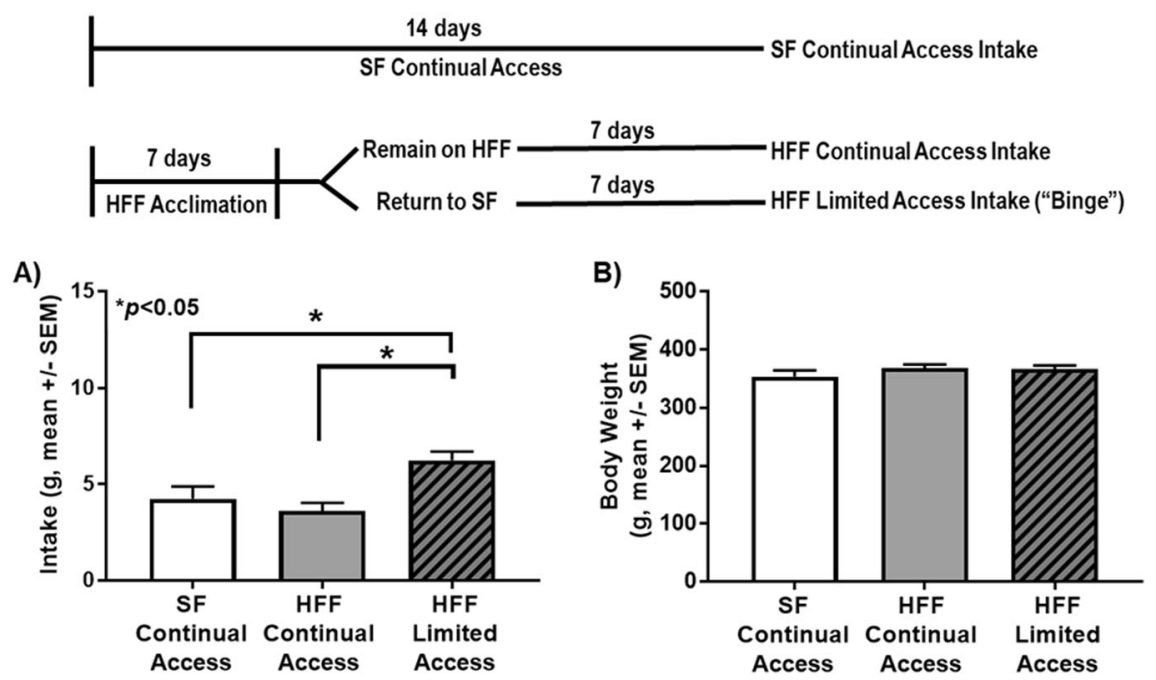

Fig. 1 Establishment of high-fat food binge-like eating paradigm. [Top] Schematic representation of experimental design. a Intake in rats is significantly greater during limited access (i.e. "binge-like episodes") high-fat food (HFF) relative to rats maintained on continual standard food (SF) or continual HFF access $\left({ }^{*} p<0.05\right)$. b No differences in body weight between SF continual access, HFF continual access or HFF limited access conditions were detected (n.s.)

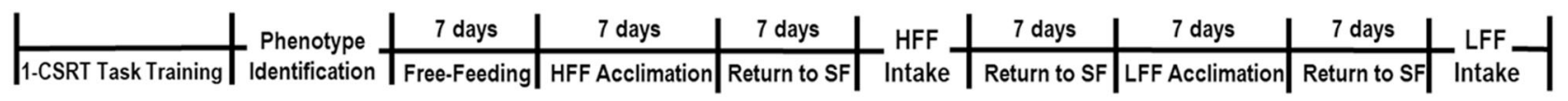

A)

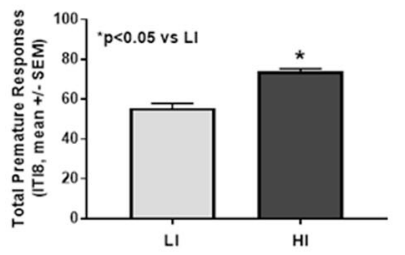

E)

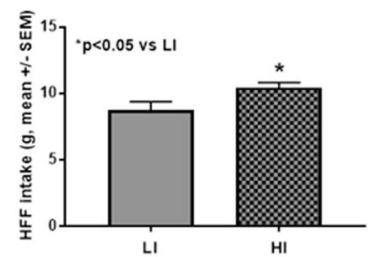

B)

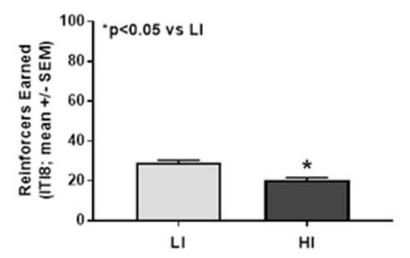

F)

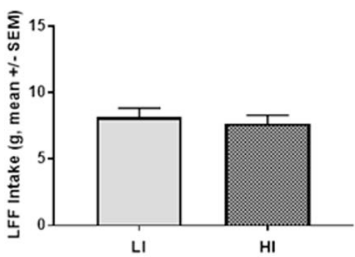

C)

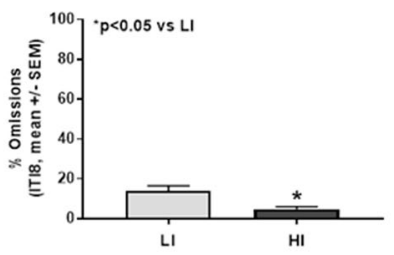

G)

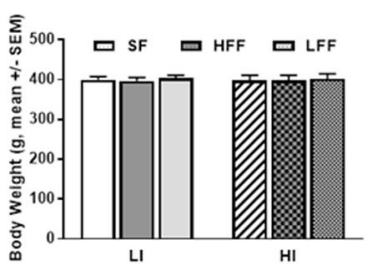

Fig. 2 Inherent motor impulsivity predicts binge-like eating of high-fat food. [Top] Schematic representation of experimental design. a HI rats displayed higher premature responses $\left({ }^{*} p<0.05 \mathrm{vs}\right.$. LI), $\mathbf{b}$ earned fewer reinforcers $\left({ }^{*} p<0.05 \mathrm{vs}\right.$. LI), and $\mathbf{c}$ made fewer omissions relative to LI rats ${ }^{*} p<0.05$ vs. LI). Following phenotype identification, the 1-CSRT task sessions were terminated and $\mathrm{HI}$ and $\mathrm{LI}$ rats were retained in their home cages and allowed to free-feed prior to feeding studies. $\mathbf{d ~ H I}$ and LI rats did not differ on standard food (SF) intake (n.s.). e HI rats exhibit greater high-fat food (HFF) intake $\left.{ }^{*} p<0.05\right)$, f but not low-fat food (LFF) vs LI rats (n.s.). g No differences in body weight between HI and LI rats following SF, HFF, or LFF were detected (n.s.)

$\left(F_{1,28}=0.67 ;\right.$ n.s. $)$, a main effect of CNO treatment $\left(F_{1,28}=6.76 ; p<\right.$ $0.05)$, and a trend towards a viral vector $\times$ treatment interaction $\left(F_{1,28}=3.50 ; p=0.07\right)$ for reinforcers earned were detected (Fig. 4b). A priori comparisons demonstrated no difference between CNO and vehicle on reinforcers earned in the DIOmCherry rats (Fig. 4b; n.s.); CNO administration augmented reinforcers earned vs. vehicle in the M3D-transduced rats (Fig. 4b; $p<0.05)$. No main effect of viral vector $\left(F_{1,28}=1.7 ;\right.$ n.s. $)$, a main effect of CNO treatment $\left(F_{1,28}=4.39 ; p<0.05\right)$, and no viral vectorxtreatment interaction $\left(F_{1,28}=0.0099 ;\right.$ n.s. $)$ for percent omissions were detected (Fig. 4c). A priori comparisons demonstrated no difference between $\mathrm{CNO}$ and vehicle on percent omissions in the DIO-mCherry rats (Fig. 4c; n.s.) or M3D-mCherry rats (Fig. 4c; n.s.).

Additional task parameters were not altered following CNO administration to either DIO-mCherry or M3D-transduced rats (Supplementary Table 2). No main effect of viral vector $\left(F_{1,28}=\right.$ $0.02 ;$ n.s.), CNO treatment $\left(F_{1,28}=1.53 ;\right.$ n.s. $)$, and a trend towards a viral vectorXtreatment interaction $\left(F_{1,28}=3.19 ; p=0.08\right)$ for target premature responses was detected (Supplementary Table 2). No main effect of viral vector $\left(F_{1,28}=1.46 ;\right.$ n.s.), CNO treatment $\left(F_{1,28}=0.94 ;\right.$ n.s. $)$, or a viral vectorxtreatment interaction $\left(F_{1,28}=2.59 ;\right.$ n.s. $)$ for non-target premature responses was detected (Supplementary Table 2). No main effect of viral vector 
A)
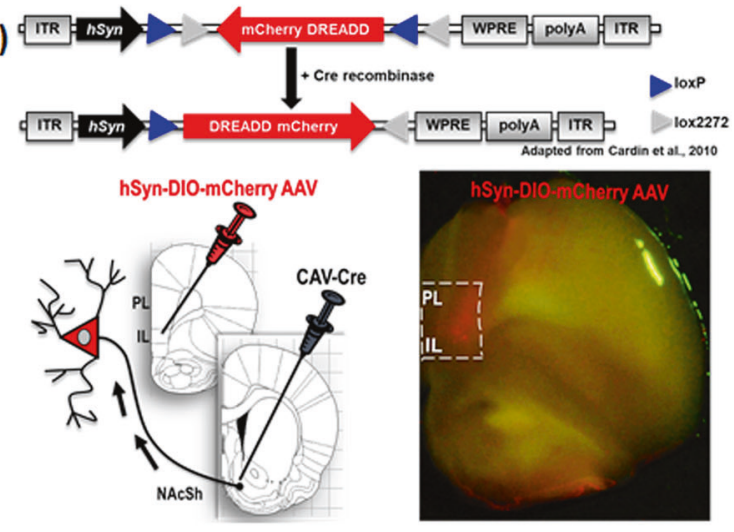

D)

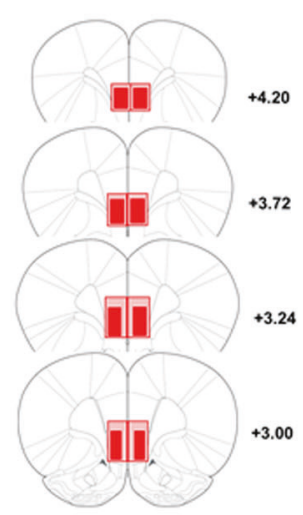

E)
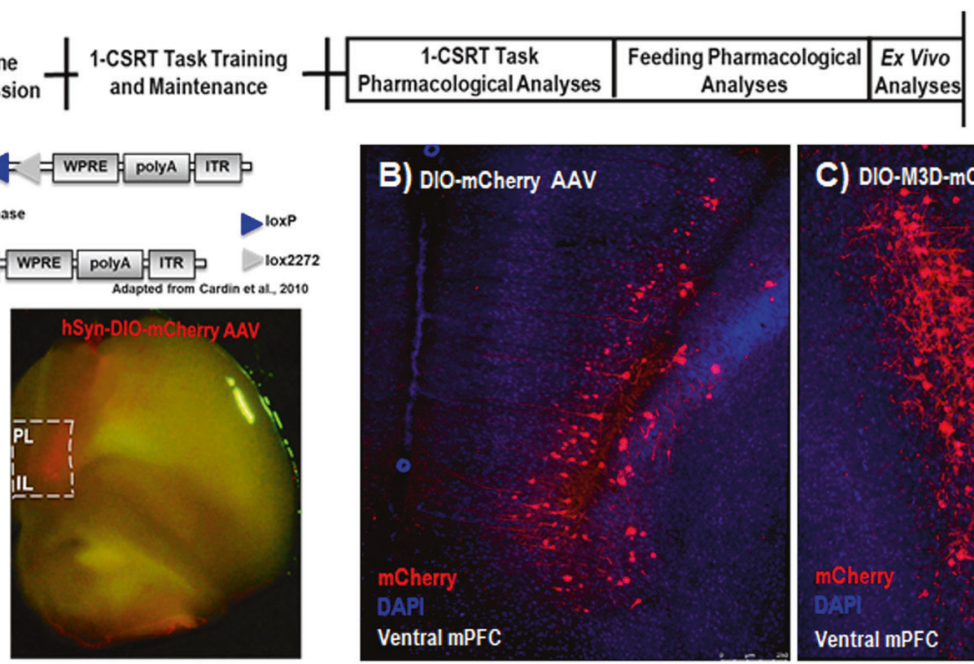
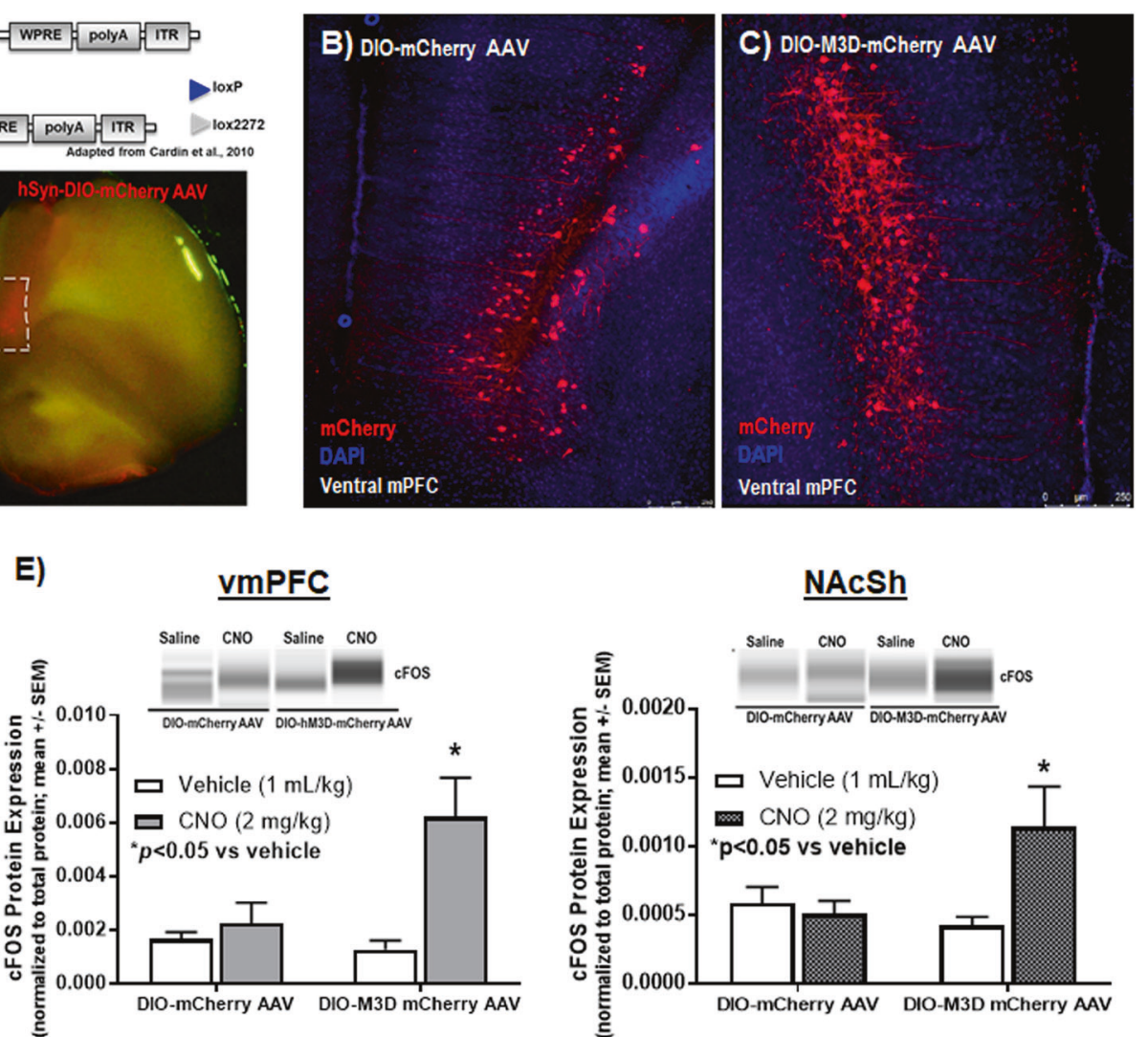

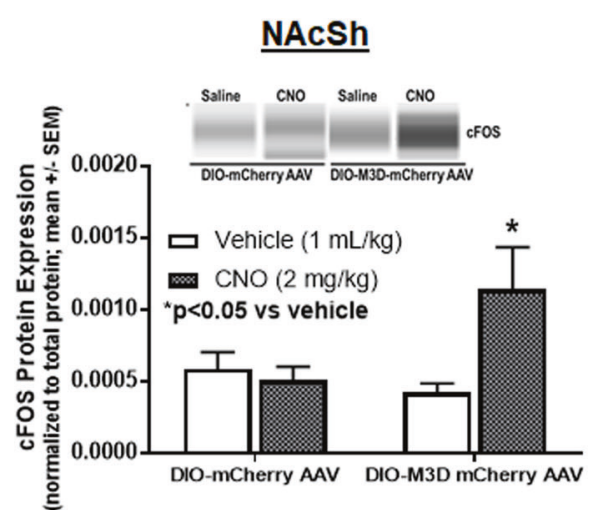

Fig. 3 Activation of vmPFC to NAcSh using dual viral vector DREADD approach. [Top] Schematic representation of experimental design. a A Cre-dependent viral vector based "double-floxed" inverted open reading frame (DIO) switch system was used to express an engineered $\mathrm{G}_{\mathrm{q}}$ DREADD (M3D). An AAV DIO construct that contains an inverted version of mCherry alone (DIO-mCherry AAV) or M3D-mCherry (DIO-M3DmCherry AAV) was infused into the vmPFC. Next, a canine adenovirus-2 (CAV)-Cre axonal retrograde viral vector was infused into the NAcSh of the same rat. Stable transgene expression in vmPFC of (b) DIO-mCherry or (c) DIO-M3D-mCherry occurred only at the site of DIO vector infusions thus restricting expression to cortical neurons that project to the NAcSh. d Illustration of the extent of viral spread in vmPFC. Red indicates robust expression in all rats and pink indicates areas of weaker expression and/or expression in a subset of rats. e Systemic administration of CNO transiently increased cFOS protein expression in vmPFC and NAcSh in DIO-M3D-mCherry AAV rats vs. vehicle $\left({ }^{*} p<\right.$ 0.05). CNO administration did not induce vmPFC or NACSh CFOS protein expression in DIO-mCherry AAV rats vs vehicle (n.s)

A)

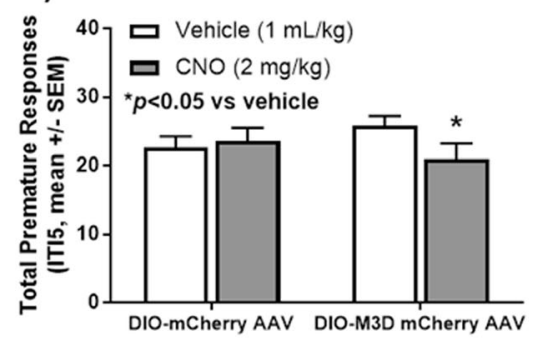

B)

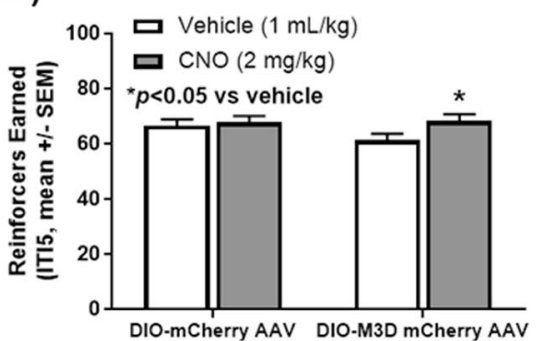

C)

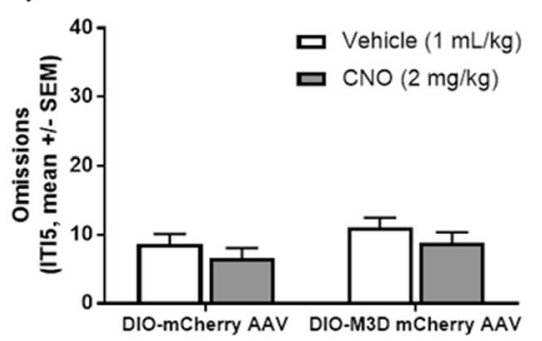

Fig. 4 Activation of vmPFC to NAcSh pathway suppresses motor impulsivity. Systemic administration of CNO to M3D-transduced rats a reduced premature responses $\left({ }^{*} p<0.05\right.$ vs vehicle) and $\mathbf{b}$ increased reinforcers earned $\left({ }^{*} p<0.05\right.$ vs vehicle) but $\mathbf{c}$ did not alter the number of omissions made (n.s.) on the ITI5 session in the 1-CSRT task. No differences between CNO administration and vehicle were observed in mCherry alone-transduced rats (n.s.)

$\left(F_{1,28}=0.09 ;\right.$ n.s. $)$, CNO treatment $\left(F_{1,28}=1.38\right.$; n.s. $)$, or a viral vector $\times$ treatment interaction $\left(F_{1,28}=0.35 ;\right.$ n.s. $)$ for accuracy was detected (Supplementary Table 2). A trend towards a main effect of viral vector $\left(F_{1,28}=3.22 ; p=0.08\right)$, no main effect of $\mathrm{CNO}$ treatment $\left(F_{1,28}=0.67 ;\right.$ n.s. $)$, and a trend towards a viral vectorxtreatment interaction $\left(F_{1,28}=3.53 ; p=0.08\right)$ for latency to the first pellet was detected (Supplementary Table 2). No main effect of viral vector $\left(F_{1,28}=0.17\right.$; n.s. $)$, CNO treatment $\left(F_{1,28}=0.37\right.$; 
n.s.), or a viral vectorxtreatment interaction $\left(F_{1,28}=0.55 ;\right.$ n.s. $)$ for time to finish the task was detected (Supplementary Table 2).

To assess the behavioral specificity of CNO and control for the potential impact of back-metabolism of CNO to clozapine [60], a subset of rats devoid of the M3D were trained in the 1-CSRT task to stability. Pretreatment with CNO did not alter total premature responses (vehicle $23 \pm 2.9 ; \mathrm{CNO}=17.8 \pm 1.4 ;$ n.s.), reinforcers earned (vehicle $=66.8 \pm 2.2 ; \mathrm{CNO}=72.8 \pm 1.4 ;$ n.s.), percent omissions (vehicle $=7.6 \pm 1.8 \%$; $\mathrm{CNO}=7.8 \pm 1.6 \%$; n.s.), accuracy (vehicle $=96.2 \pm 1.1 \%$; $C N O=97.8 \pm 0.4 \%$; n.s.), latency to the first response (vehicle $=1.54 \pm 0.4 \mathrm{~s} ; \mathrm{CNO}=1.02 \pm 0.3 \mathrm{~s}$; n.s.), or the time to finish the task (vehicle $=916.4 \pm 26.2 \mathrm{~s}$; CNO $=904.6 \pm$ $27.9 \mathrm{~s} ;$ n.s.). Clozapine administration did not alter total premature responses (vehicle $=21.6 \pm 2.3$; clozapine $=15.6 \pm 6.5$; n.s.), reinforcers earned (vehicle $=69 \pm 2.3$; clozapine $=74.4 \pm 5.1$; n.s.), percent omissions (vehicle $=7.6 \pm 1.9 \%$; clozapine $=8.2 \pm 2.9 \%$; n.s.), accuracy (vehicle $=97.4 \pm 0.9 \%$; clozapine $=97.7 \pm 0.9 \%$; n.s.), latency to the first response (vehicle $=1.6 \pm 0.2 \mathrm{~s}$; clozapine $=$ $1.95 \pm 0.6 \mathrm{~s} ;$ n.s.) or the time to finish the task (vehicle $=966.4 \pm$ $42.5 \mathrm{~s}$; clozapine $=956 \pm 45.5 \mathrm{~s}$; n.s.). These control experiments indicate that $\mathrm{CNO}$ is an effective actuator of the M3D. Thus, cumulative data indicate that selective chemogenetic activation of the vmPFC to NAcSh pathway evokes a stable, modest suppression of motor impulsivity.

Given the association between high motor impulsivity and binge-like intake of HFF, but not LFF, we assessed the role of the vmPFC to NAcSh pathway in the regulation of HFF binge-like eating. Activation of this circuit attenuated HFF binge-like intake without altering body weight (Fig. 5). No main effect of viral vector $\left(F_{1,24}=0.75 ;\right.$ n.s. $)$, a main effect of treatment $\left(F_{1,24}=10.13 ; p<\right.$ $0.05)$, but no viral vector $x$ treatment interaction $\left(F_{1,24}=0.24\right.$; n.s. $)$ for HFF intake was detected (Fig. 5a). A priori comparisons demonstrated no difference between $\mathrm{CNO}$ and vehicle on HFF intake in the DIO-mCherry rats (Fig. 5a; n.s.); CNO administration attenuated HFF intake vs. vehicle in the M3D-transduced rats (Fig. 5a; $p<0.05)$. No main effect of viral vector $\left(F_{1,24}=1.01\right.$; n.s.), treatment $\left(F_{1,24}=0.14 ;\right.$ n.s. $)$, or viral vector $x$ treatment interaction $\left(F_{1,24}=1.59 ;\right.$ n.s.) for body weight was detected (Fig. 5b). A subset of rats devoid of the M3D were administered CNO or clozapine prior to the HFF binge-like intake paradigm [32]. CNO administration did not alter HFF intake vs. vehicle as we have reported previously [32]. Clozapine administration did not alter HFF intake $(7.8 \pm 0.5 \mathrm{~g})$ vs. vehicle $(8.3 \pm 1.0 \mathrm{~g}$; n.s.). Thus, stimulation of the vmPFC to NAcSh acts as a brake to regulate HFF binge-like eating in rodents.

\section{DISCUSSION}

This study shows that motor impulsivity and binge-like eating behavior in rodents may share overlapping biological mechanisms, in particular, engagement of the vmPFC to NAcSh pathway.
We employed a rat model of binge-like eating behavior in which "binge" rats allowed 2-h access to high-fat food at the start of the dark cycle consume significantly greater calories relative to control rats maintained on continual access to standard diet or high-fat food. Individual differences in inherent motor impulsivity were identified as previously reported [40, 41, 43, 44]. High inherent motor impulsivity predicted the magnitude of binge-like eating on high-fat food, but not intake of standard food or low-fat food in rats. Thus, high-fat food may be more rewarding to $\mathrm{HI}$ rats, and prepotent responding and binge-like intake would be more difficult to withhold in $\mathrm{HI}$ rats. Given that the M3D depolarizes neurons through $\mathrm{Ga}_{\mathrm{q}}$ signaling and release of calcium from intracellular stores [61], we demonstrate for the first time that enhancing excitatory drive on VmPFC efferents to the NAcSh suppresses prepotent responding and HFF binge-like intake. Thus, these data indicate that motor impulsivity and binge-like eating are affected at the level of an imbalance in signaling within the corticoaccumbens pathway.

The mPFC is particularly important in decision-making, and heightened impulsivity signals a failure of "top-down" executive control by the mPFC over connectivity with basal ganglia control of reward responsivity [62]. Our results further support a steering role for the MPFC in both motor impulsivity and binge-like eating of high-fat food. Disruptions in both excitatory glutamate and inhibitory GABA neurotransmission within cortical regions are thought to dictate some of the behavioral consequences observed during behavioral disinhibition. Evidence from rodent studies suggests that disrupted GABAergic activity in cortical regions may contribute to dysregulated inhibitory control and increased impulsivity (for review [62]). A significant proportion of glutamatergic efferents originating in the MPFC targets areas that are highly implicated in drug- and food-reward related behaviors, such as the NAc and dorsal striatum, with the target of the efferents responsible for differentially regulating behavior [62-64].

Hedonic value of food, or feelings of "liking" and "wanting" is governed by neuronal signaling within the NAcSh [65] (for review [66]). Ingestion of highly palatable foods/energy-dense diets, which contain high levels of refined carbohydrates and dietary fat, activates neurons within the mesolimbic reward circuit, including the NAc $[27,28]$. Interestingly, enkephalin signaling in the NAc is specific for dietary fat, not carbohydrates; [67] the HFF diet is composed of $45 \%$ fat and $35 \%$ carbohydrate (by kcal and the LFF diet is composed of $10 \%$ fat and $70 \%$ carbohydrate (by kcal). Further, hypoactivation in the ventral striatum/NAc in individuals with BED occurs during anticipation of reward and continued binge eating behavior even after treatment [68]. Deep brain stimulation of the NAcSh reduces binge-like eating in mice [69] while optogenetic stimulation of the NAcSh inhibits feeding behavior in mice and drives reward-driven behaviors, i.e., "wanting", via distinct components of a hedonic network, e.g., mPFC, NAcSh [70]. Thus, the NAc plays a role in the integration of
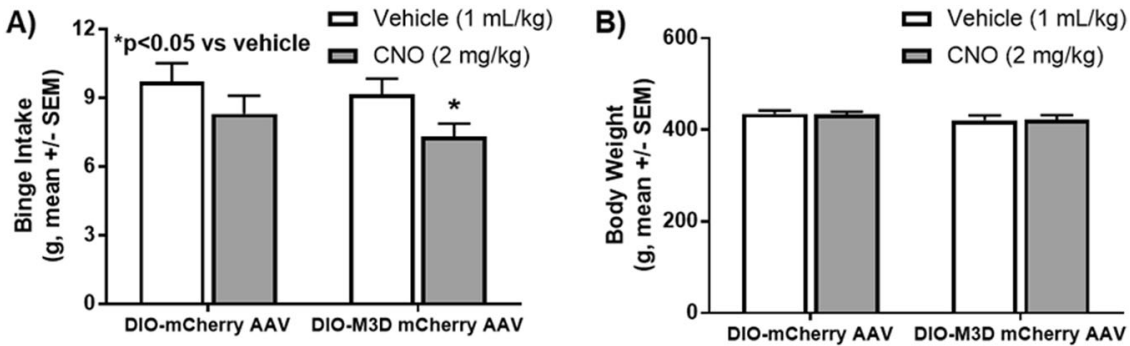

Fig. 5 Activation of vmPFC to NAcSh pathway suppresses binge-like eating of high-fat food. Systemic administration of CNO to M3Dtransduced rats a reduced binge intake of high-fat food (HFF) $\left({ }^{*} p<0.05\right.$ vs vehicle). No differences between CNO administration and vehicle were observed in mCherry alone-transduced rats (n.s.). b No differences in body weight between CNO administration and vehicle were detected in mCherry alone-transduced (n.s.) or M3D-transduced rats (n.s.) 
feeding, and its dichotomous afferents (i.e., direct vs. indirect pathway) may govern diet-dependent feeding behaviors. Nonetheless, we acknowledge that the drive to consume food is regulated by both homeostatic nutritional requirements to maintain energy balance and hedonic/reward mechanisms [71] and that mechanisms involving reward and motivated behavior in regulating food consumption are not only critical for energy balance [71, 72], but may also be conveyed by the macronutrient profile of the food. The causal relationship between inherent levels of motor impulsivity, binge-like eating, and the behavioral response to activation of the MPFC to NAcSh pathway is not known, but future studies are warranted. Nonetheless, these clinical and preclinical studies, taken together with our present findings, suggest that activation of neurons from the vmPFC to NAcSh can modulate disorders characterized by a loss of impulse control [e.g., BED, substance use disorders (SUDs)].

Natural variation in impulsive behavior may increase group survival during fluctuations in food resources that require alternating strategies of rapid, quick movements or patient, watchful waiting [73], and examination of this variance as in our studies provides the opportunity to uncover the specific cognitive and neurobiological facets that underlie extreme, maladaptive impulsivity [74]. For example, impulsivity, as scored using the BIS11 , correlates with larger test meal intake in individuals with BED [7], is elevated in individuals with BED compared to those without BED [6], and predicts early engagement of binge eating in adolescents [75]. Interestingly, we discovered that high impulsive, but not low impulsive, animals binged to a greater extent on highfat food vs. low-fat food, indicating the profile of fat:carbohydrate content in the diet together with specific brain circuits and/or neurobiological substrates may be engaged depending on the macronutrient profile [76] to contribute to the association between motor impulsivity and binge-like eating behaviors. Future studies in which the hedonic and/or motivating response as well as the neurobiological substrates recruited to specific macronutrients relative to inherent motor impulsivity levels are warranted.

Analysis of individual differences in behavior among a population of rats captures the relationship between impulsivity and binge eating that has been reported for humans. Specifically, rodent studies implicate that phenotypic differences in motor impulsivity predict both binge-like eating and an "addictivedimensionality" of eating [14, 72], similar to our findings herein as well as to observations for psychostimulants $[41,77,78]$. The DSM5 diagnostic criteria for SUDs includes compromised control, risky use, etc [2]. When the term "abused substance" is expanded to describe non-drug reinforcers, fulfillment of these criteria can be met for BED, which is defined by the DSM- 5 as recurring episodes of uncontrollable excessive intake of food [2]. Thus, similarities between SUDs and BED emerge such that the criteria describing SUDs (e.g., craving, loss of control) can be applied to other disorders with an "addictive dimensionality" [14, 72]. Collectively, these studies provide a conceptual and methodological framework for the extension of human research into animal models that may yield mechanistic insights into motor impulsivity and binge-like eating behaviors with potential clinical implications.

The identification of accurate predictive biomarkers is essential for effective application to patient treatment. Studies have previously demonstrated that neural activation patterns during tests assessing impulsivity can predict relapse in SUDs (for review [79]). However, few studies have assessed if these neural activation patterns can be used to predict specific treatment response. Behaviors such as impulsivity can be easily measured by employing questionnaires (e.g., BIS-11) and behavioral task measures (e.g., Go/No-Go task, continuous performance task, stop signal task) [80] and there is evidence to support this approach may work in predicting effective treatments in eating disorders. Treatment of BED with lisdexamfetamine suppresses both binge eating and BIS-11 scores, particularly on the motor and nonplanning impulsivity subscales [11]. To determine if impulsivity levels are a predictive biomarker for response to lisdexamfetamine, it would be beneficial to conduct a correlational analysis where a subject's binge eating activity after lisdexamfetamine treatment (e.g., percent suppression of binge episodes) is analyzed in relation to that individual's baseline impulsivity scores. To our knowledge, this analysis has not been conducted in humans, but future studies based on our current results could explore this possibility.

BED is a complex disease associated with substantial disruptions in behaviors and neural function. Our studies elucidate the relationship between impulsivity and binge-like eating and contribute to the goal to determine the significance of this neurocognitive profile for discerning neuropsychiatric disorders marked by high impulsivity. Through addressing a fundamental gap in our knowledge of how the neural aspects of impulsivity relate to binge-like eating, we hope to incorporate our findings to ultimately develop improved therapeutic strategies to minimize motor impulsivity and enhance clinical practice for disorders of overeating.

\section{FUNDING AND DISCLOSURE}

This work was supported by NIDA grants T32 DA007287 (A.E.P., D. J.S., and B.D.D.R.), F30 DA042617 (A.E.P), R01 DA036582 (S.M.F.), R01 MH106532 (J.F.N.), R01 DK106229 (J.D.H.), P50 DA033935 (K.A. C., F.G.M., and N.C.A.), K05 DA020087 (K.A.C.), R00 DA033374 (N.C. A.), The Klarman Family Foundation (K.A.C., J.D.H., and N.C.A.) and the Center for Addiction Research at the University of Texas Medical Branch. J.F.N. served on the Alexion Scientific Advisory Board. F.G.M. has current research funding from Indivior Pharmaceuticals and Nektar therapeutics for research unrelated to this study. The authors declare no competing interests.

\section{ACKNOWLEDGEMENTS}

We thank Michelle Kelly, Ph.D. for her assistance in the packaging of the CAV-2 Cre virus.

\section{ADDITIONAL INFORMATION}

Supplementary Information accompanies this paper at (https://doi.org/10.1038/ s41386-019-0394-8)

Publisher's note: Springer Nature remains neutral with regard to jurisdictional claims in published maps and institutional affiliations.

\section{REFERENCES}

1. Kessler RC, Berglund PA, Chiu WT, Deitz AC, Hudson Jl, Shahly V, et al. The prevalence and correlates of binge eating disorder in the World Health Organization World Mental Health Surveys. Biol Psychiatry. 2013;73:904-14.

2. American Psychiatric Association APADSMTF. Diagnostic and statistical manual of mental disorders: DSM-5. 5th ed. American Psychiatric Association; Arlington, VA, USA, 2013.

3. Kessler RM, Hutson PH, Herman BK, Potenza MN. The neurobiological basis of binge-eating disorder. Neurosci Biobehav Rev. 2016;63:223-38.

4. Schag K, Schonleber J, Teufel M, Zipfel S, Giel KE. Food-related impulsivity in obesity and binge eating disorder--a systematic review. Obes Rev. 2013;14: 477-95.

5. Moeller FG, Barratt ES, Dougherty DM, Schmitz JM, Swann AC. Psychiatric aspects of impulsivity. Am J Psychiatry. 2001;158:1783-93.

6. Nasser JA, Gluck ME, Geliebter A. Impulsivity and test meal intake in obese binge eating women. Appetite. 2004;43:303-7.

7. Galanti K, Gluck ME, Geliebter A. Test meal intake in obese binge eaters in relation to impulsivity and compulsivity. Int J Eat Disord. 2007;40:727-32.

8. Guerrieri R, Nederkoorn C, Stankiewicz K, Alberts H, Geschwind N, Martijn C, et al. The influence of trait and induced state impulsivity on food intake in normalweight healthy women. Appetite. 2007;49:66-73. 
9. Mobbs O, Crepin C, Thiery C, Golay A, Van der LM. Obesity and the four facets of impulsivity. Patient Educ Couns. 2010;79:372-7.

10. Castellini G, Lo SC, Mannucci E, Ravaldi C, Rotella CM, Faravelli C, et al. Diagnostic crossover and outcome predictors in eating disorders according to DSM-IV and DSM-V proposed criteria: a 6-year follow-up study. Psychosom Med. 2011;73: 270-9.

11. McElroy SL, Mitchell JE, Wilfley D, Gasior M, Ferreira-Cornwell MC, McKay M, et al. Lisdexamfetamine dimesylate effects on binge eating behaviour and obsessivecompulsive and impulsive features in adults with binge eating disorder. Eur Eat Disord Rev. 2016;24:223-31.

12. Cano AM, Murphy ES, Lupfer G. Delay discounting predicts binge-eating in Wistar rats. Behav Process. 2016;132:1-4.

13. Vickers SP, Goddard S, Brammer RJ, Hutson PH, Heal DJ. Investigation of impulsivity in binge-eating rats in a delay-discounting task and its prevention by the $\mathrm{d}$ amphetamine prodrug, lisdexamfetamine. J Psychopharmacol. 2017;31:784-97.

14. Velazquez-Sanchez C, Ferragud A, Moore CF, Everitt BJ, Sabino V, Cottone P. High trait impulsivity predicts food addiction-like behavior in the rat. Neuropsychopharmacology. 2014;39:2463-72.

15. Alexander WH, Brown JW. Medial prefrontal cortex as an action-outcome predictor. Nat Neurosci. 2011;14:1338-44.

16. Hege MA, Stingl KT, Kullmann S, Schag K, Giel KE, Zipfel S, et al. Attentional impulsivity in binge eating disorder modulates response inhibition performance and frontal brain networks. Int J Obes. 2014;39:353-60.

17. Fregni F, Orsati F, Pedrosa W, Fecteau S, Tome FA, Nitsche MA, et al. Transcranial direct current stimulation of the prefrontal cortex modulates the desire for specific foods. Appetite. 2008;51:34-41.

18. Goldman RL, Borckardt JJ, Frohman HA, O'Neil PM, Madan A, Campbell LK, et al. Prefrontal cortex transcranial direct current stimulation (tDCS) temporarily reduces food cravings and increases the self-reported ability to resist food in adults with frequent food craving. Appetite. 2011;56:741-6.

19. Chudasama Y, Passetti F, Rhodes SE, Lopian D, Desai A, Robbins TW. Dissociable aspects of performance on the 5 -choice serial reaction time task following lesions of the dorsal anterior cingulate, infralimbic and orbitofrontal cortex in the rat: differential effects on selectivity, impulsivity and compulsivity. Behav Brain Res. 2003;146:105-19.

20. Dalley JW, Everitt BJ, Robbins TW. Impulsivity, compulsivity, and top-down cognitive control. Neuron. 2011;69:680-94.

21. Warthen DM, Lambeth PS, Ottolini M, Shi Y, Barker BS, Gaykema RP, et al. Activation of pyramidal neurons in mouse medial prefrontal cortex enhances food-seeking behavior while reducing impulsivity in the absence of an effect on food intake. Front Behav Neurosci. 2016;10:63.

22. Vertes RP. Differential projections of the infralimbic and prelimbic cortex in the rat. Synapse. 2004;51:32-58.

23. Fineberg NA, Potenza MN, Chamberlain SR, Berlin HA, Menzies L, Bechara A, et al. Probing compulsive and impulsive behaviors, from animal models to endophenotypes: a narrative review. Neuropsychopharmacology. 2010;35:591-604.

24. Witt AA, Lowe MR. Hedonic hunger and binge eating among women with eating disorders. Int J Eat Disord. 2014;47:273-80.

25. Dalton M, Blundell J, Finlayson G. Effect of BMI and binge eating on food reward and energy intake: further evidence for a binge eating subtype of obesity. Obes Facts. 2013;6:348-59.

26. Finlayson G, Arlotti A, Dalton M, King N, Blundell JE. Implicit wanting and explicit liking are markers for trait binge eating. A susceptible phenotype for overeating. Appetite. 2011;57:722-8.

27. Kelley AE, Baldo BA, Pratt WE. A proposed hypothalamic-thalamic-striatal axis for the integration of energy balance, arousal, and food reward. J Comp Neurol. 2005:493:72-85.

28. Kelley AE, Baldo BA, Pratt WE, Will MJ. Corticostriatal-hypothalamic circuitry and food motivation: integration of energy, action and reward. Physiol Behav. 2005;86:773-95.

29. Benzon CR, Johnson SB, McCue DL, Li D, Green TA, Hommel JD. Neuromedin U receptor 2 knockdown in the paraventricular nucleus modifies behavioral responses to obesogenic high-fat food and leads to increased body weight. Neuroscience. 2014;258:270-9.

30. Price AE, Anastasio NC, Stutz SJ, Hommel JD, Cunningham KA. Serotonin $5-\mathrm{HT}_{2 \mathrm{C}}$ receptor activation suppresses binge intake and the reinforcing and motivational properties of high-fat food. Front Pharmacol. 2018;9:821.

31. Price AE, Brehm VD, Hommel JD, Anastasio NC, Cunningham KA. Pimavanserin and lorcaserin attenuate measures of binge eating in male Sprague-Dawley rats. Front Pharmacol. 2018;9:1424.

32. Price AE, Stutz SJ, Hommel JD, Anastasio NC, Cunningham KA. Anterior insula activity regulates the associated behaviors of high fat food binge intake and cue reactivity in male rats. Appetite. 2019;133:231-9.

33. Kremer EJ, Boutin S, Chillon M, Danos O. Canine adenovirus vectors: an alternative for adenovirus-mediated gene transfer. J Virol. 2000;74:505-12.
34. Wunsch AM, Yager LM, Donckels EA, Le CT, Neumaier JF, Ferguson SM. Chemogenetic inhibition reveals midline thalamic nuclei and thalamo-accumbens projections mediate cocaine-seeking in rats. Eur J Neurosci. 2017;46:1850-62.

35. Kerstetter KA, Wunsch AM, Nakata KG, Donckels E, Neumaier JF, Ferguson SM. Corticostriatal afferents modulate responsiveness to psychostimulant drugs and drug-associated stimuli. Neuropsychopharmacology. 2016;41:1128-37.

36. Corwin RL, Avena NM, Boggiano MM. Feeding and reward: perspectives from three rat models of binge eating. Physiol Behav. 2011;104:87-97.

37. Corwin RL, Wojnicki FH. Binge eating in rats with limited access to vegetable shortening. Curr Protoc Neurosci. 2006;36:9.23B.1-9.23B.11 Chapter 9: Unit9.

38. Anastasio NC, Gilbertson SR, Bubar MJ, Agarkov A, Stutz SJ, Jeng Y, et al. Peptide inhibitors disrupt the serotonin $5-\mathrm{HT}_{2 \mathrm{C}}$ receptor interaction with phosphatase and tensin homolog to allosterically modulate cellular signaling and behavior. J Neurosci. 2013;33:1615-30.

39. Anastasio NC, Stoffel EC, Fox RG, Bubar MJ, Rice KC, Moeller FG, et al. Serotonin (5-hydroxytryptamine) $5-\mathrm{HT}_{2 \mathrm{~A}}$ receptor: Association with inherent and cocaineevoked behavioral disinhibition in rats. Behav Pharmacol. 2011;22:248-61.

40. Anastasio NC, Stutz SJ, Fink LH, Swinford-Jackson SE, Sears RM, DiLeone RJ, et al. Serotonin (5-HT) 5- $\mathrm{HT}_{2 \mathrm{~A}}$ Receptor $\left(5-\mathrm{HT}_{2 \mathrm{~A}} \mathrm{R}\right): 5-\mathrm{HT}_{2} \mathrm{C}$ imbalance in medial prefrontal cortex associates with motor impulsivity. ACS Chem Neurosci. 2015;6:1248-58.

41. Anastasio NC, Stutz SJ, Fox RG, Sears RM, Emeson RB, DiLeone RJ, et al. Functional status of the serotonin $5-\mathrm{HT}_{2 \mathrm{C}}$ receptor $\left(5-\mathrm{HT}_{2} \mathrm{C}\right)$ drives interlocked phenotypes that precipitate relapse-like behaviors in cocaine dependence. Neuropsychopharmacology. 2014;39:370-82.

42. Cunningham KA, Anastasio NC, Fox RG, Stutz SJ, Bubar MJ, Swinford SE, et al. Synergism between a serotonin $5-\mathrm{HT}_{2 \mathrm{~A}}$ receptor $\left(5-\mathrm{HT}_{2 \mathrm{~A}} \mathrm{R}\right)$ antagonist and $5-\mathrm{HT}_{2 \mathrm{C}} \mathrm{R}$ agonist suggests new pharmacotherapeutics for cocaine addiction. ACS Chem Neurosci. 2013;4:110-21.

43. Fink LH, Anastasio NC, Fox RG, Rice KC, Moeller FG, Cunningham KA. Individual differences in impulsive action reflect variation in the cortical serotonin 5-HT2A receptor system. Neuropsychopharmacology. 2015;40:1957-68.

44. Sholler DJ, Stutz SJ, Fox RG, Boone EL, Wang Q, Rice KC, et al. The 5-HT $2 \mathrm{~A}$ receptor $\left(5-\mathrm{HT}_{2 \mathrm{~A}} \mathrm{R}\right)$ regulates impulsive action and cocaine cue reactivity in male SpragueDawley rats. J Pharmacol Exp Ther. 2018;368:41-9.

45. Paxinos G, Watson C. The rat brain in stereotaxic coordinates. 5th ed. Burlington, MA: Elsevier Academic Press; 2005.

46. Daly TM. Overview of adeno-associated viral vectors. Methods Mol Biol. 2004;246: 157-65.

47. Bubar MJ, Stutz SJ, Cunningham KA. 5-HT(2C) receptors localize to dopamine and GABA neurons in the rat mesoaccumbens pathway. PLoS ONE. 2011;6:e20508.

48. Liu S, Bubar MJ, Lanfranco MF, Hillman GR, Cunningham KA. Serotonin ${ }_{2 C}$ receptor localization in GABA neurons of the rat medial prefrontal cortex: implications for understanding the neurobiology of addiction. Neuroscience. 2007;146:1667-88.

49. Swinford-Jackson SE, Anastasio NC, Fox RG, Stutz SJ, Cunningham KA. Incubation of cocaine cue reactivity associates with neuroadaptations in the cortical serotonin (5-HT) 5-HT2C receptor (5-HT2CR) system. Neuroscience. 2016;324:50-61.

50. Dalley JW, Theobald DE, Eagle DM, Passetti F, Robbins TW. Deficits in impulse control associated with tonically-elevated serotonergic function in rat prefrontal cortex. Neuropsychopharmacology. 2002;26:716-28.

51. Winstanley CA, Zeeb FD, Bedard A, Fu K, Lai B, Steele C, et al. Dopaminergic modulation of the orbitofrontal cortex affects attention, motivation and impulsive responding in rats performing the five-choice serial reaction time task. Behav Brain Res. 2010;210:263-72.

52. Paine TA, Neve RL, Carlezon WA Jr. Attention deficits and hyperactivity following inhibition of CAMP-dependent protein kinase within the medial prefrontal cortex of rats. Neuropsychopharmacology. 2009;34:2143-55.

53. Eagle DM, Lehmann O, Theobald DE, Pena Y, Zakaria R, Ghosh R, et al. Serotonin depletion impairs waiting but not stop-signal reaction time in rats: implications for theories of the role of $5-\mathrm{HT}$ in behavioral inhibition. Neuropsychopharmacology. 2009;34:1311-21.

54. Ferguson SM, Phillips PE, Roth BL, Wess J, Neumaier JF. Direct-pathway striatal neurons regulate the retention of decision-making strategies. J Neurosci. 2013;33:11668-76.

55. Economidou D, Theobald DE, Robbins TW, Everitt BJ, Dalley JW. Norepinephrine and dopamine modulate impulsivity on the five-choice serial reaction time task through opponent actions in the shell and core sub-regions of the nucleus accumbens. Neuropsychopharmacology. 2012;37:2057-66.

56. Dalley JW, Fryer TD, Brichard L, Robinson ES, Theobald DE, Laane K, et al. Nucleus accumbens $\mathrm{D} 2 / 3$ receptors predict trait impulsivity and cocaine reinforcement. Science. 2007;315:1267-70.

57. Besson M, Pelloux $Y$, Dilleen R, Theobald DE, Lyon A, Belin-Rauscent A, et al. Cocaine modulation of frontostriatal expression of Zif268, D2, and 5-HT2C receptors in high and low impulsive rats. Neuropsychopharmacology. 2013:38:1963-73. 
58. Caprioli D, Sawiak SJ, Merlo E, Theobald DE, Spoelder M, Jupp B, et al. Gamma aminobutyric acidergic and neuronal structural markers in the nucleus accumbens core underlie trait-like impulsive behavior. Biol Psychiatry. 2014;75:115-23.

59. Cardin JA, Carlen M, Meletis K, Knoblich U, Zhang F, Deisseroth K, et al. Targeted optogenetic stimulation and recording of neurons in vivo using cell-type-specific expression of Channelrhodopsin-2. Nat Protoc. 2010;5:247-54.

60. Thompson KJ, Khajehali E, Bradley SJ, Navarrete JS, Huang XP, Slocum S, et al. DREADD agonist 21 is an effective agonist for muscarinic-based DREADDs in vitro and in vivo. ACS Pharmacology \& Translational. Science. 2018;1:61-72.

61. Alexander GM, Rogan SC, Abbas Al, Armbruster BN, Pei Y, Allen JA, et al. Remote control of neuronal activity in transgenic mice expressing evolved $G$ proteincoupled receptors. Neuron. 2009;63:27-39.

62. Koob GF, Volkow ND. Neurobiology of addiction: a neurocircuitry analysis. Lancet Psychiatry. 2016;3:760-73.

63. Gabbott PL, Warner TA, Jays PR, Salway P, Busby SJ. Prefrontal cortex in the rat: projections to subcortical autonomic, motor, and limbic centers. J Comp Neurol. 2005;492:145-77.

64. Castro DC, Cole SL, Berridge KC. Lateral hypothalamus, nucleus accumbens, and ventral pallidum roles in eating and hunger: interactions between homeostatic and reward circuitry. Front Syst Neurosci. 2015;9:90.

65. Kelley $A E$, Berridge $K C$. The neuroscience of natural rewards: relevance to addictive drugs. J Neurosci. 2002;22:3306-11.

66. Baldo BA, Kelley AE. Discrete neurochemical coding of distinguishable motivational processes: insights from nucleus accumbens control of feeding. Psychopharmacology. 2007;191:439-59.

67. Zhang M, Gosnell BA, Kelley AE. Intake of high-fat food is selectively enhanced by $\mathrm{mu}$ opioid receptor stimulation within the nucleus accumbens. J Pharm Exp Ther. 1998;285:908-14.

68. Balodis IM, Grilo CM, Kober H, Worhunsky PD, White MA, Stevens MC, et al. A pilot study linking reduced fronto-Striatal recruitment during reward processing to persistent bingeing following treatment for binge-eating disorder. Int J Eat Disord. 2014;47:376-84.
69. Halpern CH, Tekriwal A, Santollo J, Keating JG, Wolf JA, Daniels D, et al. Amelioration of binge eating by nucleus accumbens shell deep brain stimulation in mice involves D2 receptor modulation. J Neurosci. 2013;33:7122-9.

70. Prado L, Luis-Islas J, Sandoval OI, Puron L, Gil MM, Luna A, et al. Activation of glutamatergic fibers in the anterior NAc shell modulates reward activity in the aNAcSh, the lateral hypothalamus, and medial prefrontal cortex and transiently stops feeding. J Neurosci. 2016;36:12511-29.

71. Saper CB, Chou TC, Elmquist JK. The need to feed: homeostatic and hedonic control of eating. Neuron. 2002;36:199-211.

72. Volkow ND, Wang GJ, Tomasi D, Baler RD. The addictive dimensionality of obesity. Biol Psychiatry. 2013;73:811-8.

73. Stevens JR, Hallinan EV, Hauser MD. The ecology and evolution of patience in two New World monkeys. Biol Lett. 2005;1:223-6.

74. Jupp B, Caprioli D, Dalley JW. Highly impulsive rats: modelling an endophenotype to determine the neurobiological, genetic and environmental mechanisms of addiction. Dis Model Mech. 2013;6:302-11.

75. Pearson CM, Zapolski TC, Smith GT. A longitudinal test of impulsivity and depression pathways to early binge eating onset. Int J Eat Disord. 2015;48:230-7.

76. Smith AE, Kasper JM, Ara, Anastasio NC, Hommel JD. Binge-type eating in rats is facilitated by neuromedin $U$ receptor 2 in the nucleus accumbens and ventral tegmental area. Nutrients. 2019;11:E327.

77. Belin D, Mar AC, Dalley JW, Robbins TW, Everitt BJ. High impulsivity predicts the switch to compulsive cocaine-taking. Science. 2008;320:1352-5.

78. Diergaarde L, Pattij T, Poortvliet I, Hogenboom F, dV W, Schoffelmeer AN, et al. Impulsive choice and impulsive action predict vulnerability to distinct stages of nicotine seeking in rats. BiolPsychiatry. 2008;63:301-8.

79. Garrison KA, Potenza MN. Neuroimaging and biomarkers in addiction treatment. Curr Psychiatry Rep. 2014;16:513.

80. Hamilton KR, Littlefield AK, Anastasio NC, Cunningham KA, Fink LH, Wing VC, et al. Rapid-response impulsivity: definitions, measurement issues, and clinical implications. Personal Disord. 2015;6:168-81. 